which are useful and important. Such a book makes a valuable contribution towards the clarification of views held at the present time about one of the most commonly prescribed drugs. The correct use of this drug in a number of clinical conditions is clearly laid down and it should be of interest to many that the toxicity, analeptic and pressor activities of Amphetamine are unlikely to be caused by the same mechanism of action: an essential point not always appreciated is that the beneficial effect in helping weight reduction in the hypertensive patient is more important than the drug's pressor action, which is no contra-indication to its use. It is important that though Amphetamine is well known to be a drug of habituation, it is not now considered to be a drug of addiction. Altogether, this book should be widely read by the medical profession as it should appeal to student and practitioner alike.

$$
\text { H.C.S. }
$$

\section{PRACTICAL OBSTETRIC PROBLEMS}

By IAN Donald, M.B.E., M.D., B.S., B.A., M.R.C.S., L.R.C.P., M.R.C.O.G. Pp. xii +578 , illustrated. London: Lloyd-Luke Ltd. 1955. $45 \mathrm{~s}$.

This is a new book, freshly written by a young author, and has many of the virtues expected under these circumstances. Particularly do I like a book which, by leaving out those dreary and stereotyped chapters on anatomy, physiology, development of the ovum, and so forth, gets down straight away to its professed aim, the discussion of practical problems in obstetrics.

Such sections as those on "The Grande Multipara,' 'The Elderly Primigravida,' 'Acute Abdominal Pain,' are invaluable to both students and practitioners alike. I would also strongly recommend this book for those aspiring to higher diplomas for its logical and clear exposition on many facets of obstetrics, about which standard textbooks are evasive, non-committal or frankly antiquated in their views. The author is at particular pains to give reasons for all his opinions, but is fair in discussing opposing views.

It is only occasionally that the reader is left in doubt about what is in the author's mind-the advice given on postmaturity is uncertain and no mention is made of W.alker's work on foetal anoxia or Racker's on the benefit gained from induction. Again, is the picture of a man with a Geiger counter demonstrating localization of the placenta by, radio-isotopes informative or necessary in a book essentially 'spractical'?

But these are small points and such chapters as those on 'Resuscitation of the Newborn' (which is probably the best concise article written on this subject), 'Postpartum Collapse,' and 'Prematurity,' more than compensate any deficiency found elsewhere. The chapterfon 'Toxaemia of Pregnancy' is written by Carey, that on 'Breech and
Brow Presentation' by Gordon Garland, and $\mathrm{Dr} \cong$ Hilda Roberts has contributed one on 'Relief ot Pain.' It can be truly said that these authors? have more than sustained the high standard set by: Professor Donald.

Well produced, clearly set out, with excellent? photographs and drawings, this book can be con-fidently recommended to all interested in obstetrics $\frac{\bar{O}}{\overline{0}}$. D.W.S.G.

\section{ESSENTIALS OF ORTHOPAEDICS}

By Philip Wiles, M.S., F.R.C.S., F.A.C.S $\overrightarrow{\dot{\omega}}$ Second Edition. Pp. $x v+538$, with 400 illus trations, 7 in colour. London: J. \& A. ChurchifB Ltd. 1955. 55 s.

A critical and reliable account of modern ortho paedic practice is to be found in the second edition of this well-known book. Orthopaedic surgery covers such a wide variety of ills, many of obscurew pathology and controversial treatment, that the writer of a textbook is liable to become lost in a welter of detail. Mr. Wiles avoids confusion by arranging the subject-matter largely according to regions and the predominant clinical features. InE the first chapter he gives a clear description of his views on postural defects, and in the second $\vec{c}$ stoutly refusing to attribute all to ' disc lesions,' \&er gives a refreshing and helpful account of bat pain. Having dealt with these two difficult stके jects, he proceeds to the more straightforwards regional orthopaedics, ending up with a consideration of the more general conditions not alreadyo described. There is very little repetition. The practical nature of the book is emphasized in the stress that is laid on treatment the practitioner can carry out himself and in the paragraph on clinical examination that introduces the chapter on each region.

The book is well produced and handles com 옥 fortably. The illustrations, except for the rather. pointless colour plates, are excellent. As it now? stands it is eminently suitable for the under. graduate and general practitioner. Its consider 0 able value to the postgraduate surgery student and orthopaedic specialist would have been mucho greater if references to original papers had been more numerous and given in full. The very goods account of postural defects in the foot would have been better for a mention of the problem of the supinated forefoot. Few orthopaedic surgeons would share Mr. Wiles's optimism over arthrodesis of the hip or even the treatment of mallet fingers $\omega$ In devoting five pages to pressure at the cervicobrachial junction he deserts his own experience tob quote the findings of others. One wonders how much of this is true or relevant. -

These are, however, criticisms only of detail This is an excellent book which, in its secons edition, is fast becoming the leading textbook of orthopaedics in this country.

A.J.H. 